\title{
Ethical challenges posed by clinical trials in preterm labor: a case study
}

\author{
Sofía P. Salas \\ From Global Forum on Bioethics in Research (GFBR)'s "Ethics of Research in Pregnancy" meeting \\ Buenos Aires, Argentina. 03-04 November 2016
}

\begin{abstract}
This paper explores the ethical implications of a randomized double-blind clinical trial aimed to determine effectiveness and safety of an oxytocin receptor antagonist versus a betamimetic in the treatment of preterm labor, presented to a teaching hospital affiliated with a private university in Santiago, Chile. Though this trial protocol fulfills one of the conditions under which pregnant women could be enrolled in a clinical trial - the intervention has the potential to benefit the pregnant woman (by reducing adverse effects associated to salbutamol administration) and her fetus (if the new drug prolongs pregnancy) - there are some specific ethical issues raised. First, when to obtain consent is an important issue for clinical trials involving acute and unforeseen conditions that affect pregnant woman, e.g. preterm labor. Second, research must address the risk/benefit ratio for these two interdependent individuals, providing a good prospect of low risk and adequate benefit for both of them. Thirdly, specifically when a study is sponsored by a high-income country and conducted in a low- or middle-income country, decisions regarding ancillary care provisions for research participants should be made in advance. Lastly, researchers must consider the requirements for paternal consent based on cultural contexts.
\end{abstract}

Keywords: Research ethics, Pregnant women, Informed consent, Preterm labor, Tocolysis

\section{Background}

Preterm birth, defined as birth occurring between 20 and 36 weeks of gestation, is a major cause of perinatal morbidity and mortality. Preterm complications are the leading cause of death among children under the age of five, and in low-income settings, nearly half of births occurring before 32 weeks of gestation result in death due to lack of cost-effective care $[1,2]$. The acute use of a tocolytic drug to prolong pregnancy for up to $48 \mathrm{~h}$ can be useful in order to provide a window for administration of antenatal corticosteroid or in utero fetal transfer to an appropriate neonatal healthcare setting.

A study design aimed to compare effectiveness and safety of the oxytocin receptor antagonist (atosiban) versus a betamimetic (salbutamol) in the treatment of preterm labor was presented at the institutional review board (IRB) of a teaching hospital affiliated with a private university in

Correspondence: sofia.salas@udp.c

Program of Ethics and Public Policies in Human Reproduction, Faculty of Medicine, Universidad Diego Portales, Santiago, Chile
Santiago, Chile. In 1999, when this study protocol was submitted, there was no clear evidence on which tocolytic drug was preferable. Although the most frequently used tocolytic agents were beta-adrenergic agonists (betamimetics), maternal side effects-cardiovascular adverse events are reported in nearly $80 \%$ of the women-usually caused early discontinuation of the therapy despite its effectiveness in delaying birth for more than $48 \mathrm{~h}[1,3,4]$.

To blind the study treatment, a double-dummy technique was used (the study medications were identical in shape, size, and color). Inclusion criteria included maternal age between 16 and 44 years, intact membranes, between 24 weeks' and 34 weeks' gestation. Reported or documented uterine activity, and cervical dilation between $2 \mathrm{~cm}$ and $4 \mathrm{~cm}$ in an otherwise normal singleton pregnancy. The primary outcome was preterm birth ( $<37$ weeks); secondary outcomes were preterm birth within $48 \mathrm{~h}$ of randomization, at least two doses of corticosteroid administered prior to delivery, and preterm birth within seven days of randomization. Both groups 
received standard obstetric and neonatal care; there were no other interventions associated with their participation in the trial other than strict data registration and noninvasive neonatal follow-up.

\section{Ethical discussion}

A recent Committee Opinion of the American College of Obstetricians and Gynecologists regarding the inclusion of women as research participants recommends that pregnant women in research trials should be defined as "scientifically complex"-rather than "vulnerable"-because they are able to protect their own interests and give informed consent [5]. Accordingly, present debates have moved from justifying the inclusion of pregnant women in clinical trials to justifying their exclusion in what has been called the "second wave" [6]. A critical question is how to balance potential risks to the fetus with respect to benefits to the pregnant woman, particularly if she is enrolled in life-saving trials that could provide evidence based effective treatment $[7,8]$. Pregnant women do require special protections as research participants due to a legitimate concern about the protection of both the woman and her fetus $[9,10]$. As stated in the revised International Ethics Guidelines for Health-related Research Involving Humans of the Council for International Organizations of Medical Sciences (CIOMS), there are two conditions under which pregnant women can be enrolled in a clinical trial: 1 . when the interventions or procedures have the potential to benefit either the pregnant woman or her fetus, in which case risks must be minimized and outweighed by the prospect of potential individual benefit, or 2 . when the research has no potential direct benefits for the pregnant women, the risks must be minimized and no more than minimal, and the purpose of the research must be to obtain knowledge relevant to the particular health needs of the pregnant women or their fetuses [10]. In this case study, the intervention was necessary to treat a condition that is only present in pregnant women with premature labor and has the potential to benefit both the pregnant women (by reducing the side effects associated with use of betamimetics) and their fetuses (by delaying birth). At the time the study was presented to the local IRB, there was no legal framework related to research ethics in Chile; the law approved in 2006 regarding human scientific research does not describe specific research considerations for any sub-population, except for a ban on embryo research [11]. In this paper, we focus on the specific ethical issues raised by clinical trials conducted with pregnant women experiencing preterm labor.

\section{Timing to obtain consent}

Preterm labor is an unforeseen and acute complication that threatens neonatal survival. Pregnant women with premature uterine contractions are usually anxious and in pain, and may not be in the best condition to participate in a full consent procedure, particularly when there is limited time for decision-making [12, 13]. The local IRB suggested that the maternity ward enrolling women with the condition should implement a pre-consent procedure during usual pregnancy checkups. This allowed enough time for women to consider enrollment-before the preterm labor condition was present-with a more comprehensive understanding of the known maternal risks and potential benefits for the newborn of using the standard treatment or the new drug. A woman's refusal was documented in her medical records and her decision was respected. Only those women that had initially agreed to be enrolled were contacted for an abbreviated consent procedure if they started experiencing premature contractions. This strategy proved to be useful and did not limit recruitment. A similar approach of providing information about the study during routine pregnancy checkups to all potential participants has been implemented for other studies [14, 15]. Interestingly, a recent study that evaluated women's perspectives regarding the informed consent process in acute peripartum conditions demonstrated that women preferred trial information to be provided during the antenatal period, not at the moment the acute condition was present [13].

\section{Balance between the interests of the pregnant woman and the infant}

This clinical trial is a good example of maternal-fetal conflict, since the use of betamimetics for treatment of premature labor poses important health risks for the pregnant woman that are generally accepted in exchange for gain in neonatal survival [16]. Therefore, it is important to address the risk/benefit ratio for these two interdependent individuals - a new tocolytic drug aimed to reduce maternal side effects should be equally effective in prolonging pregnancy for benefits in neonatal survival. In evaluating this trial, the local IRB considered that there was enough pre-clinical evidence that the new drug, atosiban, had fewer maternal side effects due to its lack of cardiovascular effects, and that it could likely delay labor due to its mechanisms of action as an oxytocin receptor antagonist [4]. In addition, the protocol included the administration of alternative tocolysis in the event of treatment failure according to local clinical practice. In current practice, atosiban is one of the two first-line tocolytic drugs, whereas betamimetics have been abandoned due to side-effects [17].

\section{Ancillary care obligations}

As has been expressed elsewhere, ancillary care received by research participants is an important issue, particularly when the study takes place in low-and middle-income 
countries [18]. If the sponsor or the medical researcher does not provide this care, the research participants may not have their health needs met. However, the extent of these obligations is not always obvious. In this particular trial, it was difficult to determine the duties of the sponsor towards the pregnant woman and the child in the event a premature delivery occurs, and what, if any, ancillary care should be provided. The local IRB considered that the study could be done safely in the teaching hospital, which already provided the best standard of care for premature newborns (i.e. access to intensive care unit, antenatal corticoid administration, and surfactant use). In this case, the costs of these treatments were covered by the corresponding social security, differentiating them from the costs of treatment for adverse events regarding the participation in the protocol. The sponsor should pay for any maternal complications secondary to cardiovascular adverse effects or for fetal or newborn complications associated with the experimental drugs that were used, but not for the women's hospital bill or the intensive care unit for the premature baby in the event a premature delivery occurred. The rationale for this distinction was that proper neonatal care was already provided, so the health needs of the participants were met through standard care. However, in a different clinical scenario, e.g. a low-resource setting without a proper neonatal intensive care unit, the sponsors should provide this ancillary care, defined as the "healthcare that research participants need but that is not necessary to ensure the safety of scientific validity of the research..." $[19,20]$.

\section{Paternal consent requirements}

CIOMS guidelines argue that the requirement of individual informed consent by the pregnant woman is mandatory and that in no case should the permission of another person (spouse or partner) replace the woman's consent [10]. Though local adaptations to include the authorization of the fetus' father might be necessary in certain cultural contexts, the refusal of the woman to participate should prevail.

\section{Conclusions}

Inclusion of pregnant women as research participants for acute and unforeseen medical conditions, such as threatened premature labor, raises important ethical questions that should be carefully analyzed by the local IRB. First, it is important to implement a pre-consent process during antenatal visits that will allow pregnant women to make an informed decision before the moment the acute condition is present. Second, the IRB should carefully evaluate the risk/benefit ratio for both the pregnant woman and her fetus. Third, it is important to consider what ancillary care that the sponsor should provide. Finally, depending on the prevailing local culture, the IRB should evaluate if the partner's consent should be obtained in addition to the pregnant woman's consent.

\section{Abbreviations \\ ClOMS: Council for International Organizations of Medical Sciences; IRB: Institutional review board}

\section{Acknowledgements}

The author acknowledges the great contribution of Joseph Millum, Ph.D., Clinical Center Department of Bioethics, Fogarty International Center, National Institutes of Health, who carefully reviewed this manuscript.

Funding

The publication cost of this article was funded by the Wellcome Trust.

Availability of data and materials

Not applicable.

\section{About this supplement}

This article has been published as part of Reproductive Health Volume 14 Supplement 3, 2017: Proceedings from the Global Forum on Bioethics in Research (GFBR)'s "Ethics of Research in Pregnancy" meeting. The full contents of the supplement are available online at https://reproductivehealth-journal.biomedcentral.com/articles/supplements/volume-14supplement-3.

Authors' contributions

As the only author, I declare that I have read and approved the final manuscript.

Ethics approval and consent to participate

This paper did not include research in human subjects.

Consent for publication

Not applicable.

Competing interests

The authors declare that they have no competing interests.

\section{Publisher's Note}

Springer Nature remains neutral with regard to jurisdictional claims in published maps and institutional affiliations.

Published: 14 December 2017

\section{References}

1. Flenady $\mathrm{V}$, Reinebrant HE, Liley HG, Tambimuttu EG, Papatsonis DN. Oxytocin receptor antagonists for inhibiting preterm labour. Cochrane Database Syst Rev. 2014;6:CD004452.

2. WHO fact sheet $N^{\circ} 363$. Preterm birth. November 2015. Available: http:// www.who.int/mediacentre/factsheets/fs363/en/. Accessed 27 Mar 2017.

3. $\mathrm{WHO}$ recommendations on interventions to improve preterm outcomes. 2015. Available: http://www.who.int/reproductivehealth/ publications/maternal_perinatal_health/preterm-birth-guideline/en/. Accessed 27 Mar 2017.

4. Worldwide Atosiban versus Beta-agonists Study G. Effectiveness and safety of the oxytocin antagonist atosiban versus Beta-adrenergic agonists in the treatment of preterm labour. The worldwide Atosiban versus beta-agonists study group. BJOG. 2001;108(2):133-42.

5. Committee Opinion No ACOG. 646: ethical considerations for including women as research participants. Obstet Gynecol. 2015;126(5):e100-7.

6. Lyerly $A D$, Little MO, Faden $R$. The second wave: toward responsible inclusion of pregnant women in research. Int J Fem Approaches Bioeth. 2008;1(2):5-22.

7. Little MO, Lyerly AD, Faden R. Pregnant women \& medical research: a moral imperative. Bioethica Forum. 2009;2:60-5.

8. Mastroianni AC, Henry LM, Robinson D, Bailey T, Faden RR, Little MO, Lyerly AD. Research with pregnant women: new insights on legal decisionmaking. Hast Cent Rep. 2017;47(3):38-45. 
9. Saenz C, Alger J, Beca JP, Belizán JM, Cafferata ML, Canario JA, et al. An ethics call for the inclusion of pregnant women in research: reflections of the global forum on bioethics in research. Rev Panam Salud Publica. 2017:41:1-2.

10. International Ethical Guidelines for Health-related Research Involving Humans, Fourth Edition. Geneva. Council for International Organizations of Medical Sciences (CIOMS); 2016.

11. Statute $N^{\circ} 20.120$ regarding scientific research on human beings, its genome and forbids human cloning. Ministry of Health, Chile. Enacted on September 7th, 2006. Available: https://www.leychile.cl/Navegar?idNorma= 253478. Accessed 14 Sept 2017.

12. Vernon G, Alfirevic Z, Weeks A. Issues of informed consent for intrapartum trials: a suggested consent pathway from the experience of the release trial [ISRCTN13204258]. Trials. 2006;7:13.

13. Lawton J, Snowdon C, Morrow S, Norman JE, Denison FC, Hallowell N Recruiting and consenting into a peripartum trial in an emergency setting: a qualitative study of the experiences and views of women and healthcare professionals. Trials. 2016;17:195.

14. Brocklehurst P, INFANT collaborative group. A study of an intelligent system to support decision making in the management of labour using the cardiotocograph - the INFANT study protocol. BMC Pregnancy Childbirth. 2016;16:10.

15. Shakur H, Elbourne D, Gulmezoglu M, Alfirevic Z, Ronsmans C, Allen E, Roberts I. The WOMAN trial (world maternal Antifibrinolytic trial): tranexamic acid for the treatment of postpartum haemorrhage: an international randomised, double blind placebo controlled trial. Trials. 2010;11:40.

16. Yeo GS, Lim ML. Maternal and fetal best interests in day-to-day obstetrics. Ann Acad Med Singap. 2011:40(1):43-9.

17. Walker KF, Thornton JG. Tocolysis and preterm labour. Lancet. 2016; 387(10033):2068-70.

18. Jacobson N, Krupp A, Bowers BJ. Planning for ancillary care provision: lessons from the developing world. J Empir Res Hum Res Ethics. 2016;11(2):129-34.

19. Merritt MW. Health researchers' ancillary care obligations in low-resource settings: how can we tell what is morally required? Kennedy Inst Ethics J. 2011;21(4):311-47.

20. Participants in Georgetown University Workshop on Ancillary-Care Obligations of Medical Researchers Working in Developing Countries. The ancillary-care obligations of medical researchers working in developing countries. PLoS Med. 2008;5(5):e90.

\section{Submit your next manuscript to BioMed Central and we will help you at every step:}

- We accept pre-submission inquiries

- Our selector tool helps you to find the most relevant journal

- We provide round the clock customer support

- Convenient online submission

- Thorough peer review

- Inclusion in PubMed and all major indexing services

- Maximum visibility for your research

Submit your manuscript at www.biomedcentral.com/submit 